\title{
ATIVIDADES DE PROMOÇÃO À SAÚDE FÍSICA E MENTAL DE IDOSOS: UM RELATO DE EXPERIÊNCIA NA EXTENSÃO UNIVERSITÁRIA
}

\author{
PHYSICAL AND MENTAL HEALTH PROMOTION ACTIVITIES FOR THE ELDERLY: AN
}

EXPERIENCE REPORT IN THE UNIVERSITY EXTENSION

\begin{abstract}
Aline Eyng Savi ${ }^{1}$, Elizabeth Maria Campanella de Siervi ${ }^{2}$, Silemar Maria de Medeiros da
\end{abstract} Silva $^{2}$, Tainara Calabrez ${ }^{2}$

\begin{abstract}
RESUMO
Este é um relato de experiência vivenciado pelos participantes do Projeto de Extensão "Cidadania na Terceira Idade" do Programa Território Paulo Freire, com a participação dos cursos de Artes Visuais, Arquitetura e Urbanismo e Fisioterapia da Universidade do Extremo Sul Catarinense e que teve duração entre os anos de 2018 e 2020. O projeto objetivou promover a socialização do conhecimento por meio de atividades relacionadas à discussão do envelhecimento nas esferas ambiental, psicológica e física. Foram realizados vários encontros e abordagens sobre diversos temas, destacando-se: a memória e identidade; no sentido de valorizar as trocas de experiências sobre a vida e o envelhecer. Dessa forma, o objetivo do projeto foi alcançado, pois os idosos perceptivelmente, trocaram experiências, adquiriram novos conhecimentos, sanaram suas dúvidas e, portanto, estão mais preparados para liderar as necessárias adaptações promovidas pelo envelhecimento, seja na esfera ambiental (preparando especialmente sua moradia), na psicologia (adaptando seus hábitos cotidianos e ocupando-se com atividades prazerosas) e física (ao fortalecer o corpo para as alterações inerentes do processo). Ressalta-se ainda, o enriquecimento de saberes pelos extensionistas através do contato, da vivencia das dificuldades e da construção de um diálogo mais empático com o outro.
\end{abstract}

Palavras-Chave: Idoso. Envelhecimento saudável. Projeto de Extensão. Programa Território Paulo Freire.

\footnotetext{
ABSTRACT

This is an account of the experience lived by the participants of the Extension Project "Citizenship in the Elderly" of the Território Paulo Freire Program, with the participation of the Visual Arts, Architecture and Urbanism and Physical Therapy courses of the University of ExtremoSulCatarinense, which lasted from 2018 to 2020. The project aimed to promote the socialization of knowledge through activities related to the discussion of aging in the environmental, psychological and physical spheres. Several meetings and approaches were held on various topics, highlighting: memory and identity; in order to enhance the exchange of experiences on life and aging. In this way, the project's objective was achieved, because the elderly have perceptibly exchanged experiences, acquired new knowledge, solved their doubts and, therefore, are better prepared to lead the necessary adaptations promoted by aging, be it in the environmental sphere (especially preparing their housing), in psychology (adapting

${ }^{1}$ Universidade do Extremo Sul Catarinense, Endereço postal: Rua Emilio de Menezes, 355, Criciúma-SC, CEP: 88810-260 - e-mail: arquiteta.alinesavi@ gmail.com.

2 Universidade do Extremo Sul Catarinense.
} 
their daily habits and engaging in pleasurable activities) and physical (by strengthening the body for the inherent changes in the process). It is also important to enrich the knowledge of extensionists through contact, experiencing the difficulties and building a more empathetic dialogue with each other.

Keywords: Elderly.Healthyaging.Extension Project. Paulo Freire TerritoryProgram.

\section{INTRODUÇÃO}

O número de brasileiros acima de 65 anos deve quadruplicar até 2060, confirmando a tendência de envelhecimento acelerado da população e respaldado pela maior expectativa de vida. A estimativa faz parte das projeções populacionais baseadas no censo de 2010 realizado pelo Instituto Brasileiro de Geografia e Estatística. Segundo o órgão, a população com essa faixa etária deve passar de 14,9 milhões (7,4\% do total) em 2013; para 58,4 milhões (26,7\% do total) em 2060. Nesse período, a expectativa média de vida do brasileiro deve aumentar dos atuais 75 anos para 81 anos (IBGE, 2013). Perspectivas que se possuía até o momento da pandemia, o Corona Vírus talvez tenha diminuído essa estatística, em função do número maior de idosos que foram à óbito, mas certamente não a elimina.

Através da Política Nacional do Idoso (BRASIL, 1994) e do Estatuto do Idoso (BRASIL, 2003), a legislação brasileira classifica como idosa a pessoa com 60 anos de idade ou mais. Essa idade é também, adotada pela Organização das Nações Unidas (ONU) e pela Organização Mundial da Saúde (OMS) na definição do termo para países classificados como "em desenvolvimento" (nos quais, o Brasil).

No entanto, estudos científicos apontam que as marcas etárias não são suficientes para traduzir o processo de envelhecimento (e consequentemente o termo "idoso") em sua plenitude. Determinantes ambientais (que consideram restrições com o meio), psicológicas (saúde mental) e físicas (inerentes ao corpo físico) são considerados como fatores, que combinados entre si, resultam em variações próprias para cada indivíduo, implicando em maior ou menor comprometimento (OMS, 2005), e consequentemente provocando variações além da marca etária numérica.

Envelhecer acarreta mudanças no organismo do indivíduo e, na maioria das vezes, o aparecimento de algumas doenças e limitações físicas e mentais. Entre as alterações relacionadas à idade pode haver perda da comunicação e desajuste psicossocial devido a situações específicas vivenciadas pelo idoso, como: aposentadoria, viuvez, perda de amigos, alterações na composição e na dinâmica familiar, mudança de residência e dificuldades funcionais do seu cotidiano (MESQUITA DE OLIVEIRA TEIXEIRA, et al, 2016). 
Todas essas mudanças podem resultar em riscos ao bem-estar psicológico e à boa qualidade de vida, através da vivência de sentimentos negativos, tais como: abandono, inutilidade e falta de autonomia. Porém, na medida em que fatores físicos, ambientais e psicológicos influenciam o processo de envelhecimento humano, fatores como a autoestima e estratégias de enfrentamento positivas podem agir influenciando a mobilização para adaptação e/ou superação dessas vivências (MENEZES, et al, 2018).

Os impactos do envelhecimento na sociedade implicam em grandes mudanças na sociedade, com reflexo direto sobre o trato para com a pessoa idosa e seus direitos de cidadania, o que se estende às estruturas dos serviços, aos programas de saúde e à prática dos profissionais envolvidos com essa temática. Nesse sentido, o Projeto de Extensão "Cidadania na Terceira Idade" trabalhou com os três fatores determinantes do envelhecimento supracitados - aspectos ambientais, psicológicos e físicos.

O grupo de trabalho reuniu os seguintes cursos da Universidade do Extremo Sul Catarinense: Arquitetura e o Urbanismo para discutir o ambiente construído e suas adaptações para as restrições físicas inerentes do envelhecimento; Artes Visuais na medida que explorou a relação do idoso com a arte, na sua dimensão de memória e identidade; e por fim, Fisioterapia estimulando a atividade física como prática cotidiana, em detrimento ao sedentarismo.

$\mathrm{O}$ artigo trata portanto, do relato de experiência extensionista vivenciado entre os anos de 2018 e 2020, na cidade de Criciúma, no sul do estado de Santa Catarina, Brasil. O projeto atuou por meio de encontros semanais com grupos de idosos de bairros vizinhos à Universidade. O relato apresenta: as experiências universitárias acerca das ações realizadas, os instrumentos metodológicos adotados, bem como discute as repercussões dessa vivência extensionista para a formação acadêmica e seus reflexos junto à comunidade externa.

\section{FUNDAMENTAÇÃO TEÓRICA}

A velhice é um período da vida que se constrói por valores culturais de uma sociedade. Em diversos contextos e tempos históricos, é possível perceber a velhice como estigma de improdutividade e declínio, no sentido de finitude e descarte (NERI, 2006). Contudo, nas visões atuais, é possível afirmar que não há o processo unitário de envelhecimento, mas diferentes configurações subjetivas e individuais do processo de envelhecer, que são mediadas pelo contexto cultural em que se vive (MINAYO, 2006). 
Envelhecer na contemporaneidade (especialmente a ocidental), significa pertencer a um cenário de instabilidade, gerado por intensas e ininterruptas transformações de ordem cultural. Tais oscilações ocorrem com tamanha velocidade, dificultando a acomodação dos sujeitos, especialmente no que tange a velhice (MOREIRA, NOGUEIRA, 2008). Esse cenário corrobora para o estigma do "velho", sustentando a ideia de perdas, isolamento e fragilidades que mitigam a chance de manter a dignidade ao envelhecer. Registra-se que em países "em desenvolvimento" esse processo é ainda mais iminente.

Minayo (2006) aponta o que considera principais mitos a respeito da velhice. O primeiro está na faixa etária como condicionante ao envelhecimento, que pressupõem a deterioração física do corpo associado à questão orgânica. O segundo mito está na ideia de descarte, reforçando o processo de inutilidade e dependência. Para a autora, tais mitos atuam como obstáculos para a construção de uma velhice satisfatória, perpassando inclusive, as histórias pessoais e sociais. Dessa forma, como trabalhar esses mitos no sentido de acabar com eles?

Ao considerar o envelhecimento determinado além da marca etária, pelos aspectos psicológicos, ambientais e físicos, os quais compõem o contexto de vida individual, a ciência tem amadurecido a necessidade de inserção do idoso em atividades de lazer, envolvimento com a arte, continuidade no estudo e trabalho, bem como a participação ativa no cotidiano doméstico. Emergem então, reflexões para a vivência positiva, com qualidade de vida, que considere as vulnerabilidades inerentes ao processo, mas mitigue suas consequências ao valorar o sentido de pertencimento e autonomia.

Os fatores principais para um envelhecimento bem sucedido consistem na interação com a vida, preservando elevados níveis de habilidades cognitivas e funcionais, aliada a baixa probabilidade de doenças. Outro fator é baseado na crença de que os idosos que conseguem se servir de mecanismos de regulação e compensação das perdas, alcançam uma velhice bemsucedida (SILVA, et al, 2010).

Entende-se dessa maneira que a qualidade de vida de idosos está associada ao significado de velhice dada pelos mesmos, já que são consideradas questões como as mudanças de imagens do corpo, os contrastes sociais e culturais, o passado marcado pelo trabalho e se hoje, na velhice, conseguem superar seus limites sem auxílio ou se contam com a ajuda de familiares. Essa última questão é definitiva para assegurar a qualidade de vida da pessoa idosa, pois em geral, é no lar o local onde cada indivíduo se sente importante, útil, único e desempenha o seu papel e suas atividades básicas da vida diária de forma 
independente (LIMA; LIMA; RIBEIRO, 2010).

Ao considerar o fator psicológico no envelhecimento, trata-se, entre outros, das possibilidades do fazer artístico, o que se pode denominar em alguns casos, de trabalhos manuais. Considerando a manifestação artística em si, pressupõe que os idosos possam movimentar suas vidas, resgatando (ou em alguns casos construindo) princípios de cidadania. Afinal, remetendo-nos à Machado (2008, p. 09), “[...] a arte sempre foi produzida com os meios de seu tempo", e atualmente "os meios utilizados para a produção de arte têm sofrido mudanças significativas num curto espaço de tempo" (idem, p. 23).

À medida que vão envelhecendo e consequentemente se tornando mais frágeis (incluindo fisicamente), as pessoas para o envelhecimento bem-sucedido, precisam dispor de um ambiente que seja adequado, contribuindo para o encorajamento e promoção da autonomia e independência. Nesse sentido, requer ambientes acessíveis, seguros, bem planejados e projetados voltados diretamente a esse público. Sendo capazes de influenciar no modo de vida do idoso, ao permitir que ele circule com segurança pelo espaço, e que pratique suas atividades diárias com maior facilidade e autonomia (DORNELES, 2006).

No que tange o fator físico, o tratamento fisioterapêutico para o idoso tem uma importância maior como prevenção. Em busca da melhoria da qualidade de vida, é possível trabalhar com o reforço muscular, o alongamento, a coordenação e o equilíbrio por meio de programas adequados, conforme as especificidades de cada pessoa (SILVA, 2006).

Com base na fundamentação teórica apresentada, o projeto de extensão alinhou-se ao entendimento de envelhecimento bem sucedido, considerando que os idosos desfrutem plenamente dessa fase da vida. Considera-se a proposta de envelhecimento ativo, da Organização Mundial da Saúde, que é: "processo de otimização das oportunidades de saúde, participação e segurança, com o objetivo de melhorar a qualidade de vida à medida que as pessoas ficam mais velhas" (OMS, 2005, p. 13). O envelhecimento bem-sucedido é tratado portanto, como mais que ausência de doença e manutenção da capacidade funcional; é a combinação junto com o engajamento ativo com a vida e a sociedade, ao considerar os fatores ambientais, psicológicos e físicos.

\section{PROCEDIMENTOS METODOLÓGICOS}

O projeto de extensão "Cidadania na Terceira Idade: o envelhecimento saudável no Território Paulo Freire", insere-se no Programa de Extensão Território Paulo Freire, da 
Universidade do Extremo Sul Catarinense. Este, por sua vez, tem caráter inter e multidisciplinar e atua num recorte vizinho à Universidade, composto por doze bairros, cujas características socioeconômicas são de vulnerabilidade. O Programa propõe a troca entre a IES e as comunidades, para identificar demandas na construção de projetos que possam ampliar as capacidades de autonomia de seus públicos participantes.

O projeto de extensão "Cidadania na Terceira Idade" teve portanto, o objetivo principal de promover a socialização do conhecimento por meio de atividades relacionadas à discussão do envelhecimento nas esferas ambiental, psicológica e física com vistas de encaminhar alternativas de soluções aos problemas sociais, contribuindo para a melhoria da qualidade do ambiente de vida do idoso no Território Paulo Freire.

O público alvo foram os grupos de idosos dos bairros: Cidade Mineira Nova, Cidade Mineira Velha, Jardim União, São Francisco, Santa Luzia, São Defende e Vila Manaus, cujas abrangências compõem parte do recorte do Programa Território Paulo Freire (Figura 1). Registra-se que não foi abordada a totalidade de bairros, pois os demais não possuem grupos de idosos. Tais grupos são organizados pelo poder municipal como uma ação de política pública em prol do envelhecimento saudável, com a promoção de oficinas culturais coordenadas por monitores.

Figura 1: Mapa correspondente a área de abrangência do Programa Território Paulo Freire e indicação dos grupos de idosos participantes do Projeto de Extensão Cidadania da Terceira Idade.

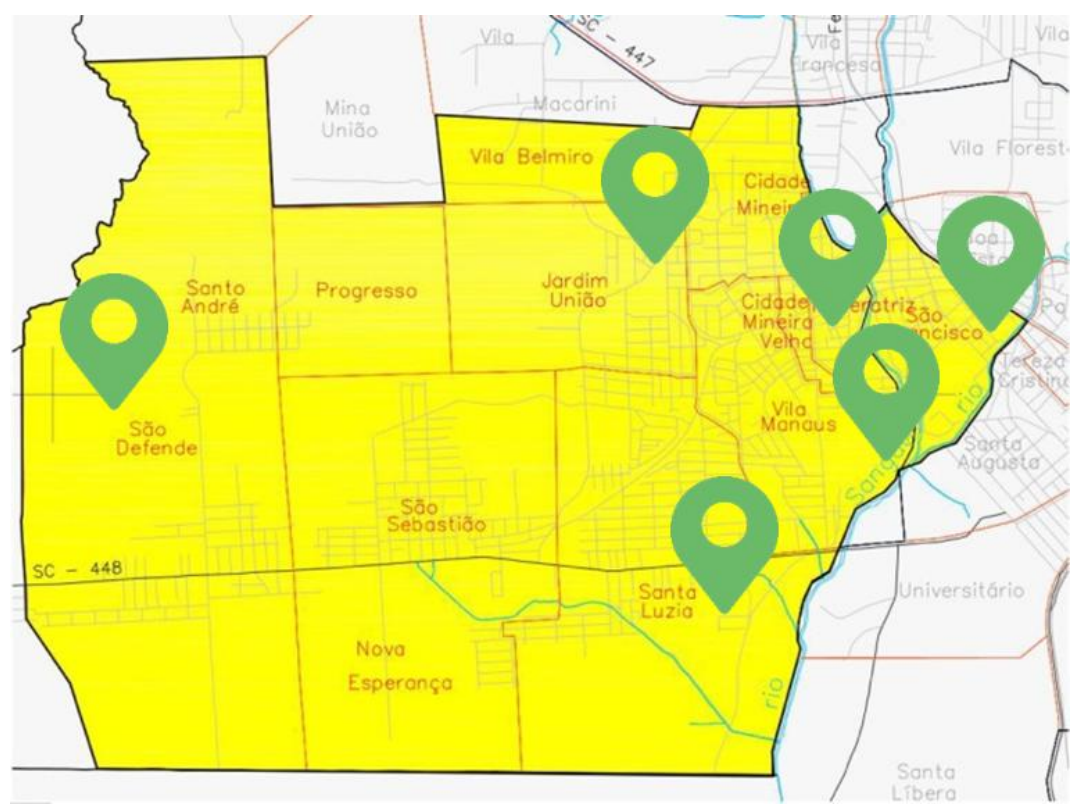

Fonte: Autores, 2018.

Para alcançar o objetivo proposto, a metodologia adotada foi participativa, mediante 
a troca de experiências acerca do tema (envelhecimento saudável) e de seus três fatores determinantes (ambiental, psicológico e físico), apoiando-se em referenciais de "pesquisa participante" de Patrício (2005) e Brandão (1998) e utilizando técnicas que envolvem diálogos reflexivos e oficinas de trabalho para "incentivar o desenvolvimento autônomo (autoconfiante) a partir das bases e uma relativa independência do exterior" (BRANDÃO, 1998, p. 43).

Olhar para a cultura destes idosos, é ampliar nossos olhares para como vivem, quais suas dificuldades, de que forma interagem uns com os outros. Nessa abordagem, a cultura da população é considerada uma disciplina, uma área de conhecimento. Esse princípio promove a integração do saber do pesquisador com o saber dos sujeitos com os quais interage, seja para ampliar a compreensão do fenômeno, seja para orientar e aplicar ações conjuntas, quando em pesquisa de cunho participante (PATRÍCIO, 2005).

As etapas de trabalho foram divididas em fases (Quadro 1), cujo processo foi continuamente avaliado a partir de reuniões da equipe, incluindo docentes e discentes extensionistas. Durante todas as fases foram produzidos registros das atividades, a partir de fotografias, áudios, vídeos e anotações de campo, que apoiaram a elaboração de relatórios de acompanhamento e a socialização dos resultados.

Quadro 1: Síntese das atividades a serem desenvolvidas.

\begin{tabular}{|c|c|c|}
\hline ETAPAS DE TRABALHO & MÉTODOS E TÉCNICAS & PARTICIPANTES \\
\hline \multirow{2}{*}{$\begin{array}{c}\text { Fase } 01 \text { - Reuniões de } \\
\text { Partida }\end{array}$} & \multirow{2}{*}{$\begin{array}{l}\text { Seminários de Socialização (acerca das } \\
\text { três esferas de trabalho, realizado em } \\
\text { cada um dos grupos de idosos e clubes } \\
\text { de mães dos bairros que compõem o } \\
\text { Território Paulo Freire) }\end{array}$} & Internas: bolsistas e professores \\
\hline & & $\begin{array}{l}\text { Externas: comunidade acadêmica } \\
\text { grupos do Território Paulo Freire }\end{array}$ \\
\hline Fase 02 - Rodas de Conversa & $\begin{array}{l}\text { Atividades práticas (acerca das três } \\
\text { esferas de trabalho, realizada em cada } \\
\text { um dos grupos de idosos e clubes de } \\
\text { mães dos bairros que compõem o } \\
\text { Território Paulo Freire) }\end{array}$ & $\begin{array}{l}\text { Externas: comunidade acadêmica } \\
\text { grupos do Território Paulo Freire }\end{array}$ \\
\hline \multirow[b]{2}{*}{ Fase 03 - Oficinas Temáticas } & \multirow{2}{*}{$\begin{array}{l}\text { Promoção de ações educativas e } \\
\text { recreativas e de troca de saberes }\end{array}$} & Internas: bolsistas e professores \\
\hline & & $\begin{array}{l}\text { Externas: comunidade acadêmica } \\
\text { grupos do Território Paulo Freire }\end{array}$ \\
\hline \multirow[b]{2}{*}{ Fase 04 - Socialização } & \multirow[b]{2}{*}{ Divulgação do aprendizado } & Internas: bolsistas e professores \\
\hline & & $\begin{array}{l}\text { Externas: comunidade acadêmica } \\
\text { grupos do Território Paulo Freire }\end{array}$ \\
\hline
\end{tabular}

Fonte: Autores, 2018.

A Fase 01, denominada de "Reuniões de Partida", constituiu na aproximação dos extensionistas com o tema e a comunidade atendida. Conforme Paulo Freire (1992), a 
responsabilidade ética, política e profissional do "ensinante" (nesse caso o extensionista) lhe coloca o dever de se preparar, capacitar e formar-se antes mesmo de iniciar sua atividade. Por essa razão, a etapa inicial consistiu em reuniões de trabalho com a definição do cronograma de atividades, a troca de informações sobre o projeto e o estabelecimento de bibliografias para aproximação conceitual pelos extensionistas (Quadro 2). Tais leituras foram socializadas primeiramente na equipe de extensão, mediante seminários temáticos. Ainda na primeira fase, foram estabelecidos os cronogramas de atividades com o público idoso.

Quadro 2: Temas estudados durante aproximação conceitual.

\begin{tabular}{|c|c|c|}
\hline $\begin{array}{c}\text { FATORES DO } \\
\text { ENVELHECIMENTO }\end{array}$ & $\begin{array}{c}\text { ÁREA DO CONHECIMENTO } \\
\text { PARTICIPANTE DO PROJETO }\end{array}$ & TEMAS ESTUDADOS \\
\hline Ambiental & Arquitetura e Urbanismo & $\begin{array}{c}\text { Acessibilidade e adaptação funcional das } \\
\text { habitações }\end{array}$ \\
\hline Psicológico & Artes Visuais & Conceito de Arte, Memória e Identidade \\
\hline Físico & Fisioterapia & Atividade física aplicada ao cotidiano \\
\hline \multicolumn{2}{|c|}{ Fonte: Autores, 2018. }
\end{tabular}

A Fase 02 - Rodas de Conversa - teve o intuito de promover a troca de experiências entre os extensionistas e a comunidade envolvida. A escolha desse modelo de abordagem considera a abordagem de Freire (1999) no que tange a ênfase ao diálogo. Elimina-se a relação de autoridade, uma vez que essa prática inviabiliza o trabalho de criticidade e conscientização, construindo o entendimento de que todo o conhecimento prévio é válido e importante (FREIRE, 1999). Em cada um dos grupos participantes foram promovidas rodas de conversa sobre o envelhecimento e as implicações nas esferas do ambiental, psicológica e física. A intenção foi motivar a comunidade para o tema e trocar experiências.

A Fase 03, designada como "Oficinas Temáticas", foi composta por atividades lúdicas e participativas acerca de cada uma das esferas. Relacionados ao ambiente, as oficinas foram práticas de observação do ambiente construído e apresentação do conceito de "casa segura", com pequenas adaptações para promover segurança e autonomia nas atividades do cotidiano. Relacionado à saúde mental, foram realizadas oficinas de arte no intuito de fomentar falas e a participação dos idosos para a promoção de qualidade de vida. Já no âmbito físico, foram realizadas oficinas sobre as boas práticas, especialmente no que tange a interação com o outro.

Com o andamento da Fase 03, foi aplicado questionário para apontar a situação de moradia dos idosos, bem como identificar as atividades cotidianas mais comuns e os empecilhos ao praticá-las. O resultado permitiu vislumbrar os principais problemas e assim 
melhor direcionar as Oficinas Temáticas de Arquitetura, Artes e Fisioterapia (supracitadas). Ainda nessa Fase, iniciaram-se junto às oficinas o registro das atividades por meio de vídeo e áudio, utilizando-se a observação participante e a entrevista informal com os idosos, como formas de captar as informações. O objetivo foi construir um documento que relatasse as experiências daqueles que participaram do projeto de extensão, apresentando as lições extraídas da prática.

A Fase 04 - Socialização - tratou de atividades de divulgação das experiências produzidas, estreitando os laços de parceria e confiabilidade entre a comunidade interna e externa à IES.

A metodologia participante organizada por meio das atividades e com a utilização dos instrumentos apresentados buscou propor reflexões do idoso sobre a percepção do corpo no espaço, numa visão mais ampla da importância idosa dentro de sua comunidade e seu âmbito familiar. Nesse sentido, os participantes se fizeram sujeitos ativos, cujas histórias foram sendo acolhidas, comungando-se com Bosi (1994, p.37), quando a mesma afirma que "nosso interesse está no que foi lembrado no que foi escolhido para perpetuar-se na história de sua vida". Exercitou-se um olhar interdisciplinar, procurando ações diferenciadas dentro daquilo que possivelmente deve ser desenvolvido pelos idosos.

Cabe ressaltar que não houve necessidade de submissão ao Comitê de Ética em Pesquisa, por se tratar de um relato de experiência com uma proposta de contribuição com relação a promover a socialização do conhecimento por meio de atividades relacionadas à discussão do envelhecimento nas esferas ambiental, psicológica e física. Questões que se deram a partir da vivência da promoção do envelhecimento saudável.

\section{RESULTADOS E DISCUSSÃO}

O recorte correspondente ao Programa Território Paulo Freire tem extensão de 19,60 $\mathrm{km}^{2}$, equivalendo a $8,36 \%$ do território municipal de Criciúma. Nesse universo, fazem parte dos seis grupos de idosos que participaram do projeto de extensão, 184 pessoas, sendo 156 do gênero feminino e 28 do masculino.

Os bairros que compõem o programa, entre eles os seis cujo projeto de extensão atuou, tem Índice de Desenvolvimento Humano considerado baixo e território com infraestrutura urbana deficitária. Relata-se tal cenário como um fator determinante para ações de valorização do idoso, promovendo inovações "incrementais" e visando preencher continuamente o processo de mudança do idoso frente a realidade de seu envelhecimento, 
conforme discute Shumpeter (1988).

A escolha pela metodologia participante permitiu compreender o público alvo como "sujeitos" e não "sujeitos do projeto de extensão"; não como passivos receptores de conhecimento e fornecedores de dados, mas como conscientes do processo e dos passos metodológicos. De forma lúdica, as atividades desenvolvidas trouxeram proposições para diálogos e troca de experiências, contemplando ações nas áreas da Arquitetura, das Artes Visuais e da Fisioterapia e aproximando-se das reais necessidades dos grupos de idosos.

Exercitou-se um olhar interdisciplinar na questão do idoso e nessa direção, corroborou-se com Bondía (2002) onde o pensar não é somente "raciocinar", "calcular" ou “argumentar", como nos tem sido ensinado algumas vezes, mas é, sobretudo dar sentido ao que somos e ao que nos acontece. Dessa forma, no exercício de valorizar o idoso direcionouse o seu olhar sensível para seus potenciais.

A Fase 01 do projeto durou o primeiro semestre, e dela participaram 12 acadêmicos e 04 professores extensionistas, organizando-se na coordenação e acompanhamento das atividades internas e junto à comunidade. As atividades foram organizadas semanalmente, a partir de calendário com definição de objetivos a serem cumpridos. Inicialmente, houve o contato com o poder municipal e as lideranças individuais dos grupos (monitoras), para a apresentação do projeto (Figura 2).

Figura 2: Apresentação do projeto às monitoras.

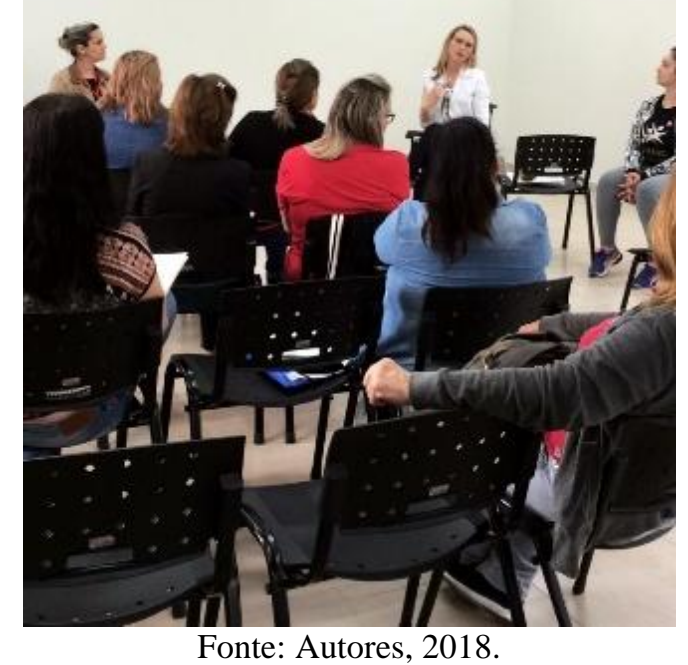

Ainda nesse período, foram realizados seminários temáticos para melhor compreensão dos temas tratados. A importância dos mesmos para o grupo e a troca de experiências entre os três cursos de graduação alinham-se a Freire (1992) no entendimento de 
que o conhecimento emerge através do questionamento inquieto, impaciente e continuado. Tal decisão permitiu que os extensionistas aproximassem de temas interdisciplinares, visto que as ações junto aos grupos de idosos foram realizados pela equipe sempre em conjunto.

$\mathrm{Na}$ Fase 02, que perdurou o segundo semestre do projeto de extensão, houve a aproximação efetiva entre os extensionistas e os grupos de idosos. Foi elaborado um calendário de visitas aos grupos, sendo um por semana e com visitas de até três horas de duração. Participaram os acadêmicos e um dos professores acompanhando o grupo. A atividade tratou da apresentação do projeto, o entendimento dos objetivos e das etapas que o mesmo possuía (Figura 3). Durante esses encontros, foi possível constatar características comuns a cada grupo: "os participativos", "os dançarinos" e "os silenciosos", por exemplo. A denominação dos grupos permitiu a construção de uma identidade por parte dos idosos, bem como dos extensionistas.

Figura 3: Apresentação do projeto ao grupo de idosos do bairro Cidade Mineira Velha.

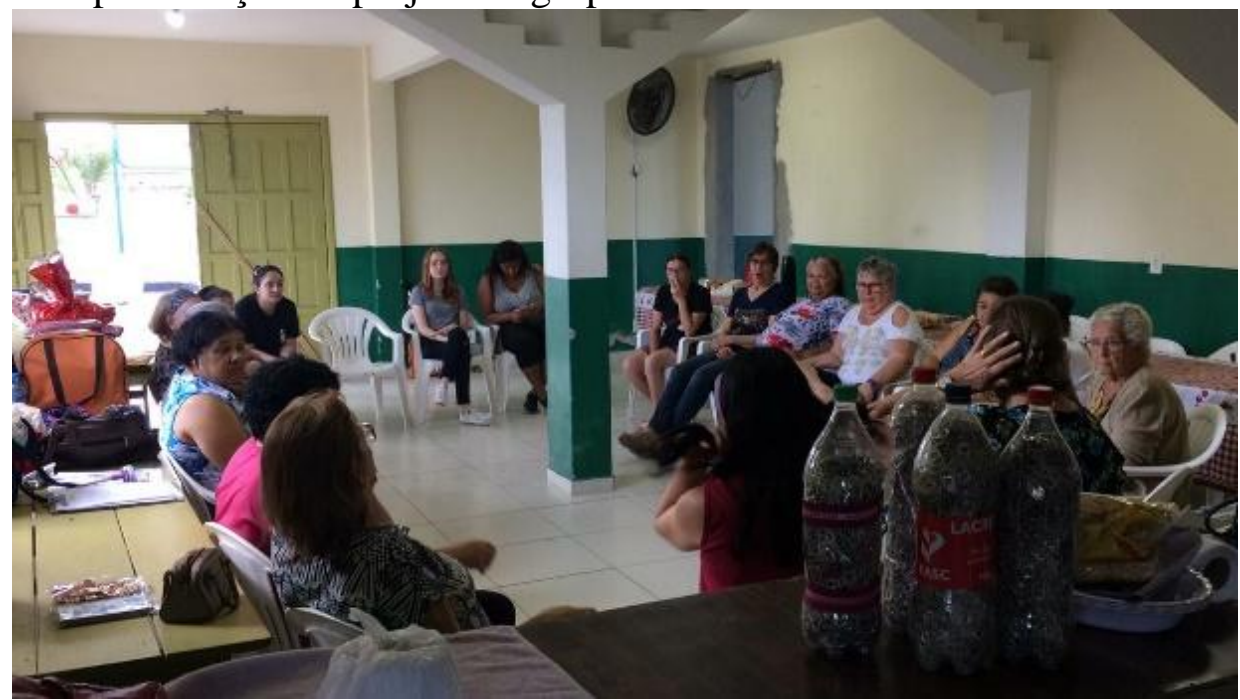

Fonte: Autores, 2018.

O espaço físico onde ocorreram as Fases 02 e 03 foram os centros comunitários dos bairros, que já acomodavam os grupos de idosos anteriormente. Esse espaço físico, na medida do possível, era organizado de acordo com o eixo temático, para que os idosos se sentissem esperados pela equipe do projeto, favorecendo o entrosamento, como também, despertando a imaginação para as atividades.

A Fase 03 teve a duração de um ano e consistiu nas oficinas temáticas, cuja abordagem foram: para a Arquitetura o tema da "casa segura"; para as Artes Visuais, a 
identidade por meio da representação artística; e para a Fisioterapia, atividades físicas no cotidiano. Registra-se que os perfis traçados na fase anterior, permitiram adequar a abordagem de cada um desses temas, corroborando para a identidade e construção da empatia no grupo. Por exemplo, para aqueles mais participativos o tema da acessibilidade na moradia do idoso fora tratado em roda de conversa; para "os dançarinos" em atividades de vivência, percorrendo um caminho; e para os "silenciosos" no modelo de palestra.

Para a realização das oficinas temáticas, foram realizadas reuniões entre os extensionistas para traçar estratégias de abordagem. $\mathrm{O}$ calendário ocorreu com um encontro semanal por grupo, com duração aproximada de duas horas e participação dos acadêmicos extensionistas. As atividades eram realizadas por meio de metodologias ativas em que, se colocava em prática atividades para facilitar o processo de troca, a interação e a comunicação entre todos os participantes (idosos e extensionistas).

Sobre o questionário aplicado nessa etapa, a amostra final obtida no decorrer da aplicação do formulário foi de 38 idosos (dos grupos de idosos Jardim União e Cidade Mineira Velha), sendo que a idade média dos participantes foi de 71 anos e a maioria pertencia ao gênero feminino. Os dados coletados revelaram que 53\% dos idosos considera escorregadio o piso do banheiro da sua moradia e 35\% que o desnível existente no boxe é fator de risco para possíveis quedas, sendo que 7\% relataram a ocorrência de queda. Ainda, $82 \%$ dos entrevistados não possuía barra de apoio no banheiro, bem como $71 \%$ possuía tapete nesse ambiente. Já com relação ao dormitório, o questionário apresentou que $42 \%$ dos idosos possui dificuldade de alcançar objetos em prateleiras mais elevadas, fato que corrobora para o dado de que $50 \%$ dos entrevistados relatou ocorrência de queda nesse local. Ao aliar isso ao fato de que grande parte ainda faz serviços domésticos, admite-se o risco ao qual estão expostos diariamente.

Os resultados demonstraram que os idosos classificam os banheiros como maior necessidade de adaptação, e que apesar do conhecimento de algumas tecnologias assistivas que minimizariam riscos de acidentes (como as barras de apoio), tem dificuldade de entendimento e de acesso financeiro a elas. Nesse sentido, as ações realizadas no que tange às oficinas temáticas da Arquitetura, buscaram elucidar ações para promoção de rotinas mais seguras na habitação, bem como as de Fisioterapia, reforçaram a prática do fortalecimento corporal para evitar acidentes domésticos (Figura 4). 
Figura 4: Atividade de fortalecimento corporal realizada no grupo de idosos do bairro Cidade Mineira Nova.

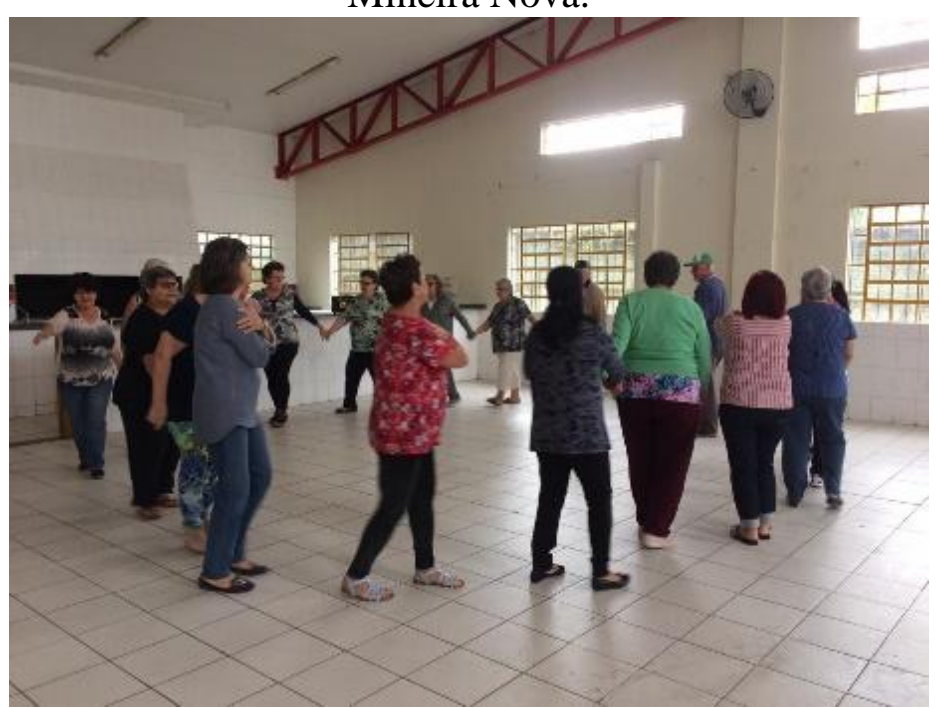

Fonte: Autores, 2018.

Ainda referente às oficinas temáticas, as visitas subsequentes abordaram a questão da memória como (re)construção da identidade social, nesse sentido da identidade do "ser idoso". A memória pode ser entendida como a capacidade que o ser humano tem de conservar e relembrar experiências e informações relacionadas ao passado, sendo estas, parte de processos de interação de cada indivíduo com seu meio. Le Goff (2013, p. 51) aponta a relação entre memória e história, quando: “Tal como o passado não é a história, mas o seu objeto, também a memória não é a história, mas um dos seus objetos e, simultaneamente, um nível elementar de elaboração histórica".

Nesse sentido, as oficinas temáticas organizaram as seguintes atividades: "caixa de memórias", onde cada idoso trazia um objeto considerado relíquia e o apresentava ao grupo; "desenho de reconhecimento" no qual eram estimuladas as representações gráficas do lugar onde se vive; e por fim, as "músicas da minha vida" onde eram resgatas cantigas de décadas sugeridas pelos idosos (Figura 5). 
Figura 5: Atividades referentes a oficina temática com ênfase na memória e identidade.

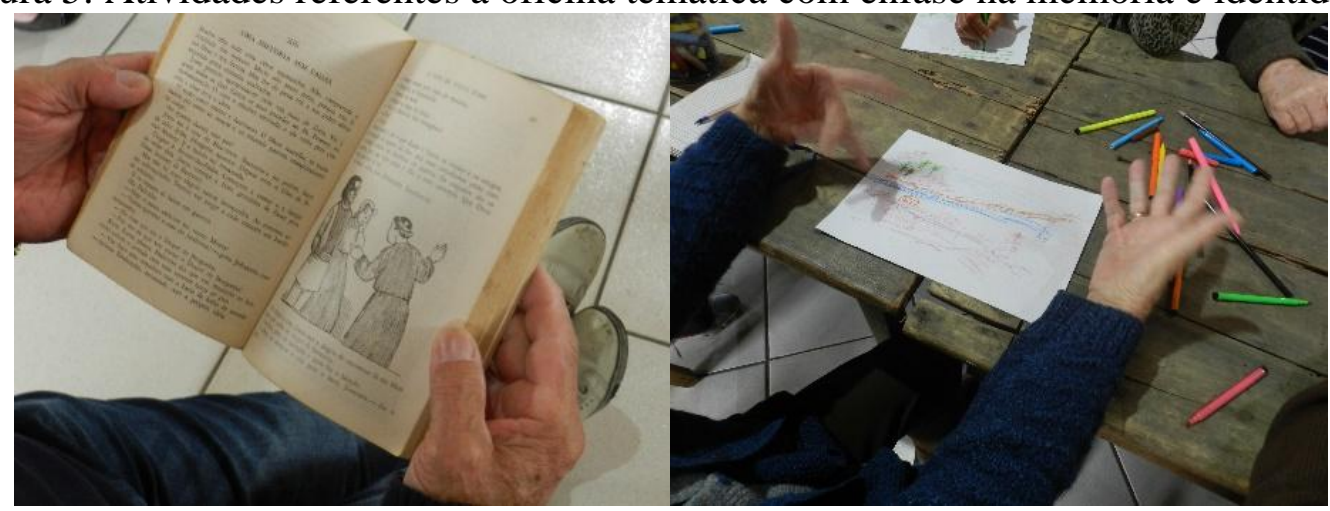

Fonte: Autores, 2019.

Tais iniciativas visavam reforçar a memória, que aparentemente é um fenômeno individual, mas deve ser entendida como um fenômeno coletivo e social. Um fenômeno construído coletivamente e submetido a flutuações e transformações, constituídos por marcos relativamente invariantes e imutáveis (POLLAK, 1992). Dessa maneira, ao resgatar objetos, lugares e músicas permitiu-se a troca de experiências entre os idosos, a construção da empatia para com o outro, mediante a aproximação das histórias vividas.

O objetivo foi que o envelhecimento da forma como tem sido tratado no projeto, enquanto constituinte do processo de desenvolvimento humano, permitisse que os agentes envolvidos o caracterizem como um tempo de exposição a acontecimentos da vida e a transições, e também como um período de implementação de estratégias de confrontação e de resolução de desafios, a partir das oportunidades e do potencial adaptativo individual.

A memória como um elemento constituinte do sentimento de identidade, tanto individual como coletiva. É também, um fator extremamente importante do sentimento de continuidade. A ruptura com o passado e o equilíbrio instável do presente não só atestam a perda da continuidade histórica, como também reforçam o estigma de velhice com o qual confronta-se a realidade atual, opondo-se os objetivos desse projeto de extensão. Por isso, a ênfase nessa temática ao longo especialmente, da Fase 03 do projeto.

A Fase 04, por sua vez, foi de socialização e inicia sua construção na etapa anterior, mediante a observação participante e as entrevistas informais. Tal postura dos discentes extensionistas permitiu inclusive o registro por vídeo (vide: https://www.youtube.com/watch?v=1vPxQE8uYw4\&feature=youtu.be).

Durante as rodas de conversa e as oficinas temáticas, os idosos participaram ativamente, expondo suas ideias e crenças sobre a velhice. Relataram o entendimento individual do processo de envelhecer, demonstrando satisfação em almejar o envelhecimento 
saudável. Nas atividades lúdicas, dispuseram-se a participar, com muita animação.

De maneira geral, ao longo das etapas foi percebida a existência de muitas dúvidas em relação ao processo de envelhecimento, especialmente em relação ao autocuidado físico e do ambiente em que se vive, corroborando para o estigma de velhice com isolamento e inutilidade. Visualizou-se também, a falta de privacidade no que tange a rotina diária, implicando na saúde física e principalmente, psicológica do idoso.

Ainda, a interação entre os atores envolvidos viabilizou-se o processo de aprendizagem, por valorizar a existência do ser humano, permitindo um assistir humanizado, vislumbrando as necessidades do indivíduo no âmbito individual e coletivo e reforçando a memória como um fator de aprendizagem e valorização do ser enquanto indivíduo, e principalmente enquanto ser social.

O projeto de extensão universitária permitiu ainda, a aproximação e troca de conhecimentos e experiências entre as comunidades internas e externas à Universidade, possibilitando o desenvolvimento de processos de ensino-aprendizagem a partir de práticas cotidianas que propiciaram o confronto da teoria com o mundo real de necessidades e desejos da sociedade. Além disso, a proposta interdisciplinar do projeto permitiu a interação de três diferentes áreas, em um relacionamento recíproco, substituindo a visão fragmentada por uma concepção unitária do ser humano. Permitindo crescimento de habilidades pessoais, como capacidade de adaptação, confiança, sensibilidade e aceitação de novos papéis.

\section{CONSIDERAÇÕES FINAIS}

O envelhecimento como aspecto do ciclo de vida e suas implicações nos fatores ambientais, psicológicos e físicos do indivíduo, compõem conteúdo de diferentes abordagens nos cursos de graduação que compuseram o projeto de extensão "Cidadania na Terceira Idade". Os extensionistas avaliaram a importância do projeto como significativa para a formação profissional, destacando também a gratificação pessoal decorrente das atividades realizadas ao longo de dois anos. Para todos, a convivência nos seis diferentes grupos de idosos possibilitou a mudança de conceitos arraigados acerca dessa faixa etária, bem como contribuiu para reflexões sobre a atuação profissional confrontadas com as realidades encontradas, de envelhecimento num cenário socioeconômico de maior dificuldade.

Em se tratando das atividades realizadas, os idosos avaliaram as oficinas temáticas como importantes para a manutenção da saúde e qualidade de vida, traduzida por uma maior preocupação consigo e com o outro, resultado das contínuas atividades promotoras de 
empatia. Ao finalizar as ações, foi nítida a percepção de que por mais simples que fossem, surtiam efeito na vida dos idosos, pois muitas vezes ficou visível a necessidade que estes tinham de informações científicas - e artísticas - para os auxiliarem no processo de envelhecimento saudável. Além do fato que muitas das orientações transmitidas de maneira lúdica, eram repassadas por eles mesmos, criando uma corrente positiva de informações.

Outro aspecto relevante, é que o projeto de extensão atendeu às recomendações da Organização Mundial da Saúde quanto à necessidade da abordagem do envelhecimento ativo com os idosos, com o objetivo de preservar a capacidade e o potencial dos indivíduos, na medida em que foram realizadas ações voltadas ao fortalecimento da autonomia, integração, saúde e socialização dos mesmos. Registra-se que a difusão de práticas de promoção do envelhecimento ativo ainda podem ser difundidas nas comunidades e por diferentes núcleos do conhecimento, visto o crescimento dessa população no país e as iminentes necessidades.

Este relato permite refletir acerca da importância da prática da extensão nas Universidades, contribuindo positivamente na população abrangida e na formação acadêmica. A importância dessas atividades como elementos agregadores na formação profissional, constituem-se num caminho teórico e metodológico na perspectiva de romper com a prática fragmentada do ensino, apostando na integralidade mediada pela inter e multidisciplinaridade.

Os cursos de graduação envolvidos nesse projeto foram ampliando seus olhares para o envelhecimento saudável, para o idoso como um ser ativo que tem muito a nos ensinar sobre seu percurso, suas fragilidades e suas potencialidades, nesta direção a dimensão desta experiência não termina aqui. Muito pelo contrário, ela tende a ecoar em diversas instâncias acadêmicas e sociais, considerando, em particular, a qualidade de vida para todos como um direito.

Com a extensão universitária, compreende-se a oportunidade de criar novos caminhos para a mudança social, os quais permitem a troca entre o conhecimento científico, adquirido pelas instituições de ensino, e o popular, já existente na comunidade de trabalho. Dessa maneira, a educação e esse modelo de atuação se tornam uma opção indispensável e viável no processo de mudança e transformação social.

\section{Agradecimentos}

Agradecimentos especiais à Universidade do Extremo Sul Catarinense (UNESC), PróReitoria Acadêmica (PROACAD) e Diretoria de Extensão, Cultura e Ações Comunitárias, aos Grupos de Idosos participantes. Bem como aos acadêmicos: Fernanda Rodrigues dos Santos, Kálita Silveira Nunez, Laura Dieke, Letícia Tomé, Miguel Rosado de Araújo, Natália Rocha 
de Moraes, Nathalia Borsatto D’agostin; e ao Professor Eduardo Ghizi cujas contribuições enriqueceram o projeto no decorrer de sua vigência.

\section{Fontes de financiamento}

Fonte de financiamento do Edital $n^{\circ} 188 / 2018$, do Programa de Extensão Território Paulo Freire.

\section{REFERÊNCIAS}

BONDÍA, Jorge Larrosa. Notas sobre a experiência e o saber de experiência. In: Revista Brasileira de Educação, 2002.

BOSI, Ecléa. Memória e Sociedade: Lembranças de velhos. $9^{\circ}$ edição, editora Schwarcz Ltda. 1994.

BRANDÃO, Carlos Rodrigues. Participar-pesquisar. In: Brandão, Carlos Rodrigues (org). Repensando a pesquisa participante. 3 ed. São Paulo: Brasiliense, 1998.

BRASIL. Lei $\mathbf{n}^{\mathbf{0}} \mathbf{1 0 . 7 4 1}$, de $1^{\circ}$ de outubro de 2003, dispõe sobre o Estatuto do Idoso e dá outras providências. Brasília: Câmara dos Deputados, Edições Câmara, 2010.

Lei n. 8.842, de 04 de janeiro de 1994. Dispõe sobre a Política Nacional do Idoso, cria o Conselho Nacional do Idoso e dá outras providências. Brasília; 1994.

DORNELES, Vanessa G. Acessibilidade para idosos em áreas livres públicas de lazer. Dissertação de Mestrado. Universidade Federal de Santa Catarina, Florianópolis, 2006.

FREIRE, Paulo. Educação como prática da liberdade. 23. ed. Rio de Janeiro: Ed. Paz e Terra, 1999.

, Paulo. Pedagogia da esperança - um reencontro com a Pedagogia do oprimido. Rio de Janeiro: Ed. Paz e Terra, 1992.

INSTITUTO BRASILEIRO DE GEOGRAFIA E ESTATÍSTICA (IBGE). Estatísticas sobre a população 2013. 2013. Disponível em: http://www.ibge.gov.br. Acesso em 14 fev. 2018.

LE GOFF, Jacques. História e memória. 7. ed. Campinas/SP: Editora da Unicamp, 2013.

LIMA, Deusdedit; LIMA, Maria Alice; RIBEIRO, Cristiane. Envelhecimento e qualidade de vida de idosos institucionalizados. RBCEH, Passo Fundo. 2010, vol. 7, n. 3, p. 346-356.

MACHADO, Arlindo. Arte e mídia. 2. ed. Rio de Janeiro: Jorge Zahar, 2008.

MENEZES, J. N.; et al. A visão do idoso sobre o seu processo de envelhecimento. In: Rev Contexto Saúde. 2018;18(35), p. 8-12.

MESQUITA DE OLIVEIRA TEIXEIRA, Selena; et al. Da velhice estigmatizada à 
dignidade na existência madura: novas perspectivas do envelhecer na contemporaneidade. In: Estudos e Pesquisas em Psicologia, vol. 16, núm. 2, 2016, p. 469-487.

MINAYO, Maria Cecilia S. Visão antropológica do envelhecimento. In: Vários colaboradores (Orgs.), Velhices: reflexões contemporâneas (vol. 1, p. 47-60). São Paulo: SESC: PUC, 2006.

MOREIRA, V.; NOGUEIRA, F. N. N. Do indesejável ao inevitável: a experiência vivida do estigma de envelhecer na contemporaneidade. Psicologia USP, 19(1), 2008, p. 59-79.

ORGANIZAÇÃO MUNDIAL DA SAÚDE. Envelhecimento ativo: uma política de saúde. Tradução Suzana Gontijo. Revisão em português Janaina Caldeira. Capa e Projeto Gráfico Fabiano Camilo. 1.ed. Brasília: Organização Pan-Americana da Saúde, 2005. 60 p.: il.

PATRÍCIO, Zuleica. M. Técnicas de Levantamento de dados. In: Introdução à prática de pesquisa socioambiental. Apostila. Curso de especialização em Gestão de Recursos Hídricos. Departamento de Engenharia Sanitária e Ambiental - UFSC, 2005. 102 p.

POLLAK, Michael. Memória e Identidade Social. In: Estudos Históricos, Rio de Janeiro, vol. 5, n. 10, 1992, p. 200-212.

SCHUMPETER. A teoria do desenvolvimento econômico. São Paulo: Nova Cultural, 1988.

SILVA, H. S., et al. Envelhecimento bem-sucedido e vulnerabilidade em saúde: aproximações e perspectivas. Interface - Comunicação, Saúde e Educação, 14(35), 2010, p. 867-877.

SILVA, Rafael Duarte; CAMPOS, Vinicius Castro. Cinesioterapia: fundamentos teóricos para prática. Belo Horizonte: COOPMED Ed., 2006. 145 p. 